\title{
Detection, Antimicrobial Susceptibility and Serotyping of Streptococcus pneumoniae from Cerebrospinal Fluid Specimens from Suspected Meningitis Patients
}

\author{
M Rabiul Alam ${ }^{1}$, Samir Kumar Saha², Tania Nasreen ${ }^{3}$, Farzana Latif ${ }^{1}$, Sabita Rezwana Rahman ${ }^{1}$ and \\ Donald James Gomes ${ }^{1 *}$ \\ ${ }^{1}$ Department of Microbiology, University of Dhaka, Dhaka 1000, Bangladesh, ${ }^{2}$ Department of Microbiology, Bangladesh Institute of Child Health, \\ Dhaka Shishu (Children) Hospital, Sher-e-Bangla Nagar, Dhaka 1207, Bangladesh, ${ }^{3}$ Food Microbiology Section, Institute of Food Science \& \\ Technology (IFST), Bangladesh Council of Scientific \& Industrial Research (BCSIR), Dr Qudrat-e-Khuda Road, Dhaka 1205, Bangladesh
}

[Received 11 December 2006; Accepted 21 April 2007]

Pneumococcal meningitis is the most important cause of community-acquired meningitis in children resulting in high morbidity and mortality worldwide. This study aimed to evaluate immunochromatographic test (ICT), a rapid detection method, for pneumococci in cerebrospinal fluid (CSF) and also to assess antibiotic susceptibility pattern of the clinical isolates. The findings of CSF-ICT of suspected meningitis cases were also compared with the results of CSF culture, latex agglutination test (LAT) and polymerase chain reaction (PCR). Among these diagnostic methods, ICT and PCR showed $100 \%$ specificity. A total of 401 CSF specimens were cultured but culture positivity was observed with $55(13.7 \%)$ cases in which Streptococcus pneumoniae was identified from $20(36.4 \%)$ culture-positive cases. A remarkably high resistance rate to gentamicin (95\%) and cotrimoxazole $(60 \%)$ among the invasive strains of $S$. pneumoniae was observed, while none of the isolates exhibited resistance to penicillin, ceftriaxone and chloramphenicol by disk diffusion test. Minimum inhibitory concentration (MIC) showed similar susceptibility pattern. The invasive strains $(\mathrm{n}=18)$ belonged to 9 different serotypes including 1, 2, 4, 34, 12A, 38, 19F, 35A and 45. The prevalent serotypes were 2 (23.5\%), $1(\mathbf{1 7 . 6 \% )}$ and $45(\mathbf{1 1 . 8 \% )}$. The study shows that a remarkable proportion of meningitis cases in children are caused by $S$. pneumoniae. Diagnostic methods like ICT and PCR can be considered as effective methods for the detection of pneumococcal meningitis even with the patients who have been treated with empirical antibiotics. Ceftriaxone is a safe choice for empirical therapy, while the use of cotrimoxazole for the treatment of meningitis infections is debatable.

Keywords: Pyogenic meningitis, Cerebrospinal fluid (CSF), Streptococcus pneumoniae Immunochromatographic test (ICT), Polymerase chain reaction (PCR), Serotying

\section{Introduction}

Meningitis receives a high level of medical, public health and media attention because of its rapid onset and high level of morbidity and mortality ${ }^{1-2}$. Apart from epidemic, at least 1.2 million cases of meningitis are estimated to occur every year with 135,000 deaths ${ }^{1}$. Acute bacterial meningitis is seen more in children than adults and it is caused by a variety of microorganisms; the most important among them are Haemophilus influenza, Neisseria meningitides and Streptococcus pneumoniae $e^{3-5}$. The prevalence of these organisms varies from place to place, by age and season $^{3,5-6}$. The specific pathogen causing bacterial meningitis varies around the World ${ }^{2,5-7}$. Various factors that determine the outcome of the disease are age, early diagnosis, early treatment, duration of treatment and type of microorganism ${ }^{7}$.

The exact aetiological diagnosis is often not possible because of poor culture facilities ${ }^{8}$. The rapid progression of symptoms and potentially devastating effects of this disease necessitate early diagnosis and immediate treatment ${ }^{9}$. Rapid identification has important public health implications, particularly with regard to case contact management, detection and evaluation of clusters of cases and intervention of outbreaks ${ }^{10}$. Developments in pneumococcal polysaccharide protein conjugate vaccines have increased the need for accurate laboratory confirmation of these infections in order to monitor the effect of vaccine implementation and their continuing efficacy ${ }^{11}$.

In many cases of meningitis it was evident that specimen was collected after the patient received antibiotic ${ }^{12}$. Detection of aetiology of these cases by culture method, which is considered as 'gold standard', becomes difficult ${ }^{12}$. For such instances alternate methods should be employed including detection of antigen by latex agglutination test (LAT) ${ }^{13}$, or detection of the Lyt A gene by

*Corresponding author:

Dr. Donald James Gomes, Professor, Department of Microbiology, University of Dhaka University, Dhaka 1000, Bangladesh

Tel (Office): (02) 9661920-73, Ext. 7739; Tel (Home): (02) 8362232; Cell: 01817 016815;Fax: +880 (02) 8615583; E-mail: donaldjgomes@hotmail.com 
polymerase chain reaction $(\mathrm{PCR})^{10,14}$. LAT is an expensive method, while PCR is considered as standard but is still not accessible for rapid diagnosis because it is an expensive method. Another method is immunochromatographic test (ICT), initially developed to detect pneumococcal antigen in urine collected from patients with invasive pneumococcal disease ${ }^{15}$. On the other hand, this test can be used for identifying the presence of antigen in CSF with 95-100\% sensitivity and $100 \%$ specificity for pneumococcal meningitis when compared with CSF culture ${ }^{14,16}$.

Another concern that becomes a threatening problem is the resistance or decreased susceptibility to antibiotics among the clinical isolates of $S$. pneumoniae, which increased dramatically in the last decade ${ }^{2,17-18}$. Bangladesh is not devoid of this situation due to the worldwide migration of the antibiotic resistant clones of S. pneumoniae along with the migration of the pneumoccoccal carrier or pneumoccoccal infected individuals ${ }^{19}$. A preliminary report from Bangladesh showed that $10 \%$ of $S$. pneumoniae strains were resistant to penicillin ${ }^{20}$. If the this rate of antibiotic resistance continues, all the antibiotics designed for S. pneumoniae will be ineffective against pneumococcal infection and that would be a threatening condition for the human health. But studies on the prevalence, serotypes and detection of antibiotic resistant clones and their distribution are few in Bangladesh. To understand this crucial problem, it is necessary to know the prevalence of pneumococcal meningitis, their antibiotic resistance and prevalent serotypes in Bangladesh.

The purpose of this study was to detect $S$. pneumoniae from pyogenic cases of meningitis by culture and rapid methods and to determine the degree of susceptibility to commonly used antimicrobial agents. We also assessed the prevalence of different S. pneumoniae serotypes isolated form cerebrospinal fluid (CSF) specimens.

\section{Materials and Methods}

Study population

During a 14-month period in the year 2004-2005, 401 children with suspected meningitis (age group: 2 to 5 years) were included. Patients who had pyogenic meningitis (CSF containing $\geq 100$ $\mathrm{WBC} / \mathrm{mm}^{3}$ with $50 \%$ neutrophils and/or growth of the organism in culture) were studied.

\section{Clinical specimens}

Cerebrospinal fluid (CSF) specimens were collected aseptically in sterile tube by lumber puncture from $3^{\text {rd }}$ and $4^{\text {th }}$ lumber region by needle aspiration by physician.

\section{Routine analysis of CSF specimen}

CSF specimen was examined and evaluated biochemically and cytologically by following standard procedure as described previously $^{21}$.

\section{Isolation of bacteria}

Conventional method was followed for isolation of the bacteria. CSF specimen $(100 \mu \mathrm{l})$ was centrifuged at 2,000 rpm for $20 \mathrm{~min}$ and the sediment was inoculated with a bacteriological loop on trypticase soy agar plate containing 5\% sheep blood. The inoculated plates were incubated in a candle extinction jar for $24-72 \mathrm{~h}$ at $37^{\circ} \mathrm{C}$. S. pneumoniae showed characteristic colonies on blood agar, which were further identified by standard methods $^{22}$.

\section{Latex agglutination test (LAT)}

LAT was done according to the manufacture's instruction (Remel, Inc, Lenexa, KS, USA). Reading of agglutination was taken by mixing $40 \mu \mathrm{l}$ of boiled CSF and one drop of test latex on the specified circle of the supplied paper slide and then mixed on a shaker for $3 \mathrm{~min}$. The result of LAT was considered positive when agglutination occurred.

\section{Immunocromatographic test (ICT)}

ICT was performed using ICT kit (Binax NOW Streptococcus pneumoniae Antigen Test; Binax Inc, Portland, ME, USA) according to the manufacturer's instruction. For CSF sample, a swab was dipped into the specimen, and then it was inserted into the test device. Reagent A, a buffer solution, was added from a dropper bottle and the device was closed that made the sample connected to the test strip. Antigens of pneumococcus, present in positive samples, bound to immobilized $S$. pneumoniae antibody and formed detectable purple line within $15 \mathrm{~min}$, which was read visually.

\section{Polymerase chain reaction (PCR)}

PCR was done for the detection of Lyt A gene by using the primers described previously ${ }^{14}$. DNA was extracted by boiling $200 \mu \mathrm{l}$ of CSF specimen for $5 \mathrm{~min}$. A 5- $\mu$ l aliquot was mixed with PCR master mix containing $2.5 \mu \mathrm{l}$ of $10 \mathrm{x}$ reaction buffer, $2.0 \mu \mathrm{l}(2.5 \mathrm{mM})$ of each deoxynucleotide triphosphate, $0.125 \mu \mathrm{l}$ (5 Units/ $\mu \mathrm{l})$ of Taq polymerase, $0.025 \mu \mathrm{l}$ of $L y t \mathrm{~A}_{\mathrm{s}}, 0.025$ of $L y t \mathrm{~A}_{\mathrm{r}}(0.1 \mu M)$ and $20.3 \mu \mathrm{l}$ of $\mathrm{dH}_{2} \mathrm{O}$ (Takara Bio Inc, Shiga, Japan). PCR conditions were $94^{\circ} \mathrm{C}$ for $2 \mathrm{~min}$, followed by 30 cycles of $94^{\circ} \mathrm{C}$ for $30 \mathrm{sec}, 55^{\circ} \mathrm{C}$ for $30 \mathrm{sec}$ and $72^{\circ} \mathrm{C}$ for sec in a Px 2 thermal cycler (Thermo Electron Co., Needham Heights, MA, USA). Further extension was done at $72{ }^{\circ} \mathrm{C}$ for $10 \mathrm{~min}$. Amplicons were visualized under UV fluorescence following electrophoresis in 3\% agarose (Invitrogen, Carlsbad, CA, USA) and stained with ethidium bromide. Positive controls of DNA from standard strains of S. pneumoniae as well as negative controls were included in each assay.

\section{Antimicrobial susceptibility}

Disk diffusion test for different antimicrobials was done by following the recommendation of the National committee for Clinical Laboratory standards ${ }^{29}$. Antimicrobial disks used included penicillin $\mathrm{G}(10 \mathrm{IU})$, ampicillin $(10 \mu \mathrm{g})$, erythromycin $(15 \mu \mathrm{g})$, cotrimoxazole $(25 \mu \mathrm{g})$, chloramphenicol $(30 \mu \mathrm{g})$, gentamicin $(10 \mu \mathrm{g})$ and ciprofloxacin $(5 \mu \mathrm{g})$. Minimum inhibitory concentrations (MICs) of penicillin, ampicillin, ceftriaxone, cotrimoxazole, chloramphenicol and erythromycin for the isolated strains were determined by E-test ${ }^{2,23}$. The test was performed on Mueller-Hinton agar supplemented with 5\% defibrinated sheep 
blood. Inoculum was prepared in Mueller-Hinton broth by direct suspension of pneumococcal colonies grown overnight on sheep blood agar and matched to a $0.5 \mathrm{McF}$ arland opacity standard tube as described by Jorgensen et al. ${ }^{24}$.

\section{Serotyping}

Isolated invasive strains of pneumococci were serotyped by following capsular swelling procedure (Quellung reaction) with type-specific anti-pneumococcal omni, pool, type or group, and factor sera (Statens Seruminstitute, Denmark) ${ }^{25}$. ATCC strains 6314, 6301, and 10341 were used as known control strains. Nontypeable S. pneumoniae strains were screened out with omni sera at the first step of serotyping.

\section{Results and Discussion}

Acute bacterial meningitis continues to be a major health concern with a fatality rate of more than $30 \%$ in some studies ${ }^{1}$. Although the countenance of bacterial meningitis has changed substantially over the past 15 years, this disease still causes significant mortality, particularly in developing countries, and neurological sequelae ${ }^{26}$. Several current studies showed difference in susceptibility pattern of $S$. pneumoniae and $H$. influenzae, another important causative agent of pyogenic meningitis ${ }^{2,14,27}$. Based on these data the empirical treatment strategy for meningitis differs.

In this study, cerebrospinal fluid (CSF) of 401 patients (age between 2 and 5 years) were evaluated by lumber puncture for clinical doubt of meningitis at Dhaka Shishu (Children) Hospital from 2004-2005. Figure 1 shows the sensitivity of different methods for detecting the pneumococcus isolates from the specimen. Among 401 meningitis cases, 55 (13.7\%) were culture positive, which included $20(36.4 \%)$ positive cases for S. pneumoniae. Overall, 25 (6.2\% of 401) cases of pneumococcal meningitis were identified, including culture-positive cases $(\mathrm{n}=20)$ and culture-negative but PCR (Lyt A) positive cases $(\mathrm{n}=5)$. Thus, sensitivity of culture for identifying S. pneumoniae was $80 \%$ ( 20 of 25 ). The ICT was positive within $3 \mathrm{~min}$ for all of the pneumococcal cases $(n=25)$. Thus, sensitivity of ICT was $100 \%(25 / 25)$ for detection of S. pneumoniae. On the other hand,

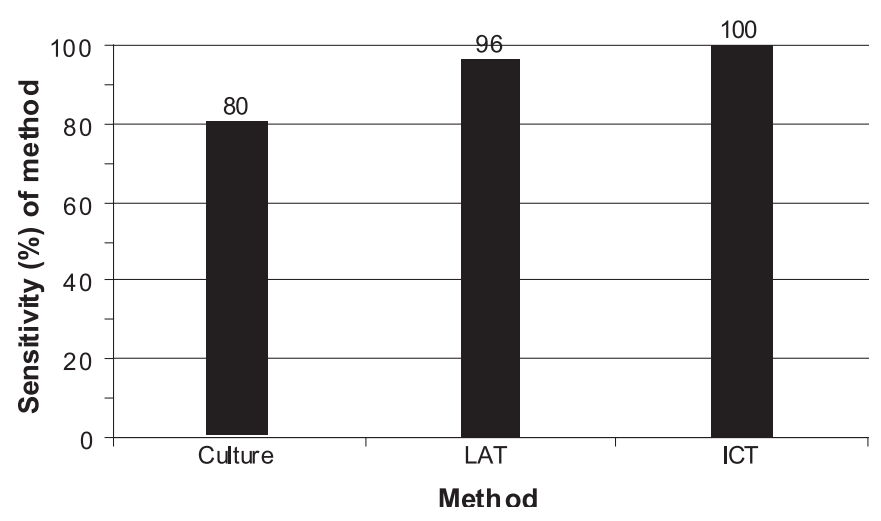

Figure 1. Sensitivity of various methods for the detection of Streptococcus pneumoniae. LAT: latex agglutination test; ICT: Immunocromatographic test.
ICT results for the CSF specimens that were culture positive for other organisms $(n=30)$ were negative. Thus, specificity of ICT was also $100 \%$ (Figure 1). Detection of LytA gene by PCR was done for all the 25 samples and the LytA was detected from all $(100 \%)$ of these samples (Figure 2).

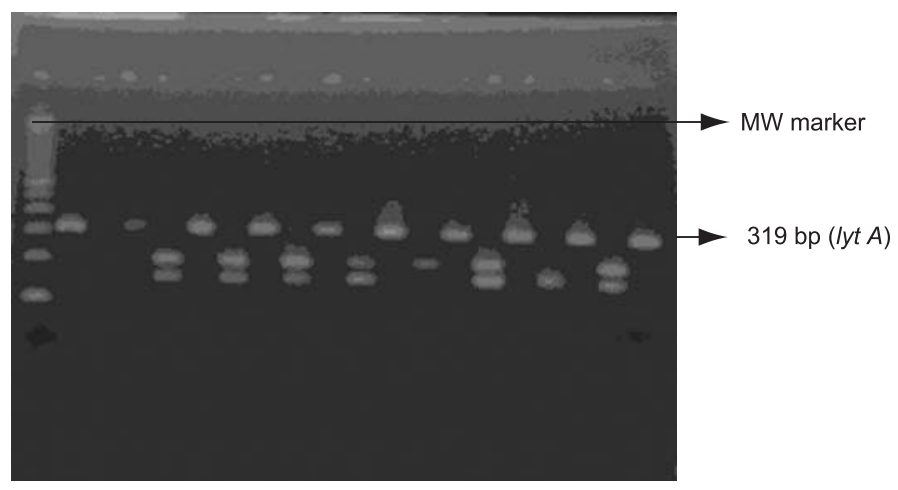

Figure 2. Agarose gel electrophoresis showing amplified products of DNA (Lyt A gene) obtained from Streptococcus pneumoniae.

This study focused that the ICT test was $100 \%$ sensitive for detection of pneumococcal meningitis case specificity compared with the non-pneumococcal cases proved by either culture or LAT or PCR. This findings of this study are similar to those of previous studies ${ }^{14}$.

Following diagnosis of meningitis empirical therapy is given to the patients in order to reduce the mortality and morbidity. In spite of the cases of potent antibiotics and improved management of the critically ill, there is a small and significant risk of death or severe neurological sequelae following bacterial meningitis in childhood $^{28}$. While antibiotics have made a major impact on outcome for such patients, the contemporary mortality rate remains unacceptably high, at approximately $25 \% 29$. A contemporary concern with treatment of meningitis is the treatment failure owing to emergence of antimicrobial resistance among the isolates ${ }^{27}$. Penicillin-resistant (MIC $\geq 2 \mu \mathrm{g} / \mathrm{ml}$ ) and multiple drug resistant strains of $S$. pneumoniae have emerged in many parts of the world ${ }^{27,30}$.

For determining the resistance pattern to different antimicrobials, pneumococcal isolates were primarily screened out by disk diffusion test (Figure 3). All isolates were found to be susceptible to penicillin, ampicillin, ceftriaxone ( $3^{\text {rd }}$ generation cephalosporin) and chloramphenicol, while resistant to gentamicin (95\%), cotrimoxazole (60\%) and erythromycin (5\%). Qualitative resistance by the disk diffusion method was quantitated further by the E-test (Figure 4) and the results are summarized in Table 1. A remarkably high rate of resistance to commonly used drugs such as gentamicin ( $80 \%$ or 16 of $20 ; \mathrm{MIC} \geq 16.0 \mu \mathrm{g} / \mathrm{ml}$ ) and cotrimoxazole ( $60 \%$ or 12 of 20 ; MIC $\geq 4 / 76 \mu \mathrm{g} / \mathrm{ml}$ ) was observed. One isolate, which showed erythromycin nonsusceptibility by disk diffusion test also showed high MIC value ( $\geq 4.0 \mu \mathrm{g} / \mathrm{ml})$. On the other hand, all were susceptible to penicillin except two for which the MICs were within intermediately resistant range $(0.1-1.0 \mu \mathrm{g} / \mathrm{ml})$. 


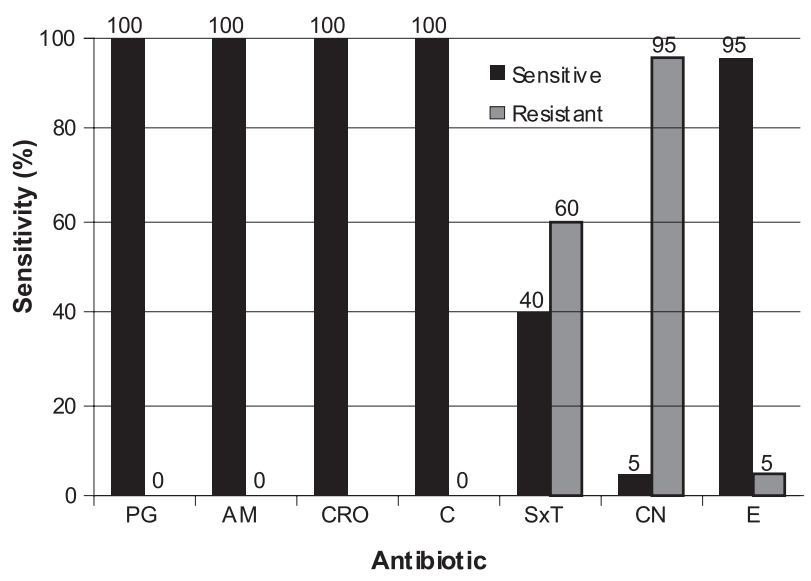

Figure 3. Antibiotic sensitivity pattern of Streptococcus pneumoniae isolated from cerebrospinal fluid specimens of patients with meningitis $(n=20) . P G=$ Penicillin $G$; $A M=$ Ampicillin; $C R O=$ Ciprofloxacin; $C=$ Chloramphenicol; SxT = Cotrimoxazole $; C N=$ Gentamicin $; E=$ Erythromycin

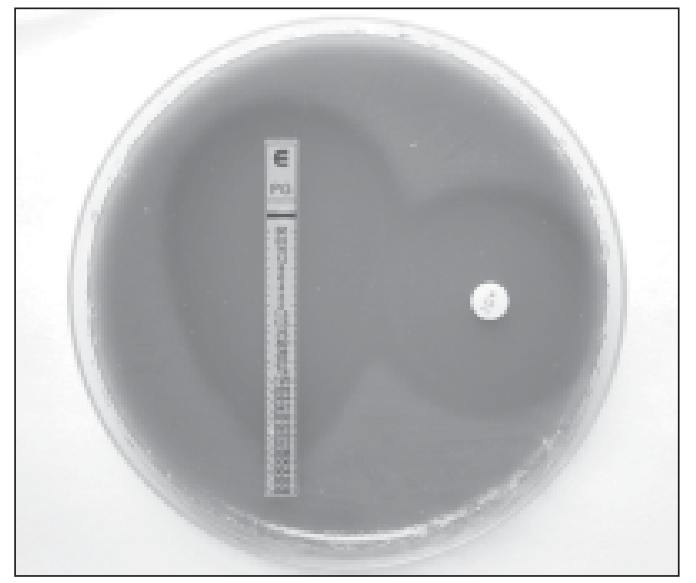

Figure 4. E-test (left) and disk diffusion (right) showing zone of inhibition represents the degree of susceptibility of Streptococcus pneumoniae to penicillin.

Table 1: Antimicrobial susceptibility by E-test of Streptococcus pneumoniae isolates $(n=20)$ recovered from cerebrospinal fluids of patient with meningitis

\begin{tabular}{lcc}
\hline $\begin{array}{l}\text { Sensitivity } \\
\text { determination }\end{array}$ & $\begin{array}{c}\text { MIC } \\
(\mu \mathrm{g} / \mathrm{ml})\end{array}$ & $\begin{array}{c}\text { Frequency, } \\
\text { No. }(\%)\end{array}$ \\
\hline Penicillin & & \\
$\quad$ Sensitive & $\leq 0.06$ & $18(90)$ \\
$\quad$ Intermediate & $0.10-1.0$ & $2(10)$ \\
$\quad$ Resistant & $\geq 2.0$ & $0(0)$ \\
Cotrimoxazole & & \\
$\quad$ Sensitive & $\leq 0.5 / 9.5$ & $6(30)$ \\
Intermediate & $1 / 19-2 / 38$ & $2(10)$ \\
Resistant & $\geq 4 / 76$ & $12(60)$ \\
Gentamicin & $\leq 4$ & $1(5)$ \\
$\quad$ Sensitive & 8 & $3(15)$ \\
Intermediate & $\geq 16$ & $16(80)$ \\
Resistant & & \\
Erythromycin & $\leq 0.5$ & $19(95)$ \\
Sensitive & $1.0-2.0$ & $0(0)$ \\
Intermediate & $\geq 4.0$ & $1(5)$ \\
$\quad$ Resistant & &
\end{tabular}

The resistance of $S$. pneumoniae to penicillin and other antimicrobial agents is increasing in many parts of the world ${ }^{31}$. Low rate of resistance for meningitis strains to penicillin (3\%) and erythromycin (1\%) but high rate of resistance to cotrimoxazole $(69 \%)$ and chloramphenicol (15.5\%) among meningitis strains has been reported in Bangladesh ${ }^{27}$, which is in partial agreement to results of the present study but, in contrary, no resistance to chloramphenicol was observed. This might be due to the small number of samples examined in this study. An increasing trend of chloramphenicol resistance has been observed in Bangladesh as it has now reached a level of $15.5 \%{ }^{14}$ compared to $2.8 \%$ in $1997^{2}$. In this study, a high prevalence (95\%) of in vitro cotrimoxazole resistance was observed, which is consistent with findings from other countries in this region ${ }^{32-33}$ and also with a previous study with invasive pneumococcal strains in Bangladesh ${ }^{2,14}$. High cotrimoxazole resistance might be due to widespread and indiscriminate use of the drug by community health workers ${ }^{34}$.

Though penicillin nonsusceptibility was not observed in disk diffusion method, two (10\%) isolates exhibited intermediately resistance by E-test. Low rates of nonsusceptibility to penicillin have been reported from Asian countries like China, India, and the Philippines ${ }^{33}$, while high prevalence of penicillin nonsusceptibility has been reported in the United States ${ }^{35}$, European countries ${ }^{36}$ and several other Asian countries ${ }^{37}$. Overall, the absence of ceftriaxone resistant $S$. pneumoniae meningitis strains indicates that ceftriaxone remains a reasonable empirical drug of choice for community-acquired meningitis in Bangladesh.

Table 2 shows the serotype distribution of the S. pneumoniae. Eighteen isolates were available for serotyping. Nine different serotypes were identified including 1, 2, 4, 34, 12A, 38, 19F, 35A and 45 , while 3 isolates could not be identified and they were grouped as 'nontypeable'. The dominant serotypes were type 2 (23.5\%) and type 1 (17.6\%). Serotype 7F was not found in this study, which was reported to be the most predominant serotype in an early study in Bangladesh ${ }^{19}$.

Table 2. Serotype distribution of Streptococcus pneumoniae isolated from cerebrospinal fluid specimens of patients with pyogenic meningitis

\begin{tabular}{lc}
\hline Serotype & Frequency, No. (\%) \\
\hline 1 & $3(17.6)$ \\
2 & $4(23.5)$ \\
4 & $1(5.9)$ \\
34 & $1(5.9)$ \\
$12 \mathrm{~A}$ & $1(5.9)$ \\
38 & $1(5.9)$ \\
$19 \mathrm{~F}$ & $1(5.9)$ \\
$35 \mathrm{~A}$ & $1(5.9)$ \\
45 & $2(11.8)$ \\
Nontypeable & $3(17.6)$ \\
Total & $18(100.0)$ \\
\hline
\end{tabular}


In conclusion, our study shows that PCR is a sensitive method for detecting pneumococcal meningitis but ICT is a simple, reliable and easily implemented method. This method is so simple that it can be done at bed side for quick detection. For cases where patients have already received antibiotics it acts as a supportive method to detect whether the case is pneumococcal or not. Secondly, a considerable number of S. pneumoniae are multidrugresistant (MDR) being resistant to first-line antibiotics, which raises concern for conducting surveillance of burden of pneumococcal meningitis and resistance pattern of the isolates. Finally, the most common serotypes of pneumococci are invasive and antibiotic resistant. The fact that most isolated strains are covered by the 23 polyvalent pneumococcal vaccine, the broader use of the vaccine could reduce the incidence of pneumococcal diseases.

\section{Reference}

1. Babiker MA \& Taha SA. 1984. Meningitis in children of Riyadh. J Trop Med Hyg. 87: 245-248.

2. Saha SK, Rikitomi N, Ruhulamin M, Masaki H, Hanif M, Islam M, Watanabe K, Ahmed K, Matsumoto K, Sack RB \& Nagatake T. 1999. Antimicrobial resistance and serotype distribution of Streptococcus pneumoniae strains causing childhood infections in Bangladesh, 1993 to 1997. J Clin Microbiol. 37(8): 2743-2744.

3. Dagbjartsson A \& Ludvigsson P. 1987. Bacterial meningitis: Diagnosis and initial antibiotic therapy. Peditr Clin N Am. 34: 219-230.

4. Schlech WF III, Ward JI, Band JD, Hightower A, Fraser DW \& Broome CV. 1985. Bacterial meningitis in the United States, 1978 through 1981: The National Bacterial Meningitis Surveillance Study. J Am Med Assoc. 253: 1749-1754.

5. Schiech WF. 1985. Bacterial meningitis in the United States. $J$ Am Med Assoc. 253: 1749-1754.

6. AL-Jurayyan NAM. 1992. Childhood bacterial meningitis in AL-Baha Provience, Saudia Arabia. J Trop Med Hyg. 95: 180-185.

7. Bridger RC. 1986. Diagnosis and treatment of bacterial meningitis. Postgrad Doctor. 9: 282-287.

8. Kabra SK, Kumar P, Verma IC, Mukherjee D, Chowdhary BH, Sengupta S, Singh RN, Khatna SP, Miglani N, Schai KM, et al. 1991. Bacterial meningitis in India: An IJP survey. Indian J Pediatr. 58(4):505-511.

9. Ausina V. 1989. Rapid laboratory diagnostic methods in respiratory infections. Curr Opin Infect Dis. 2: 541-546.

10. Lorente L, Falguera M, Nogués A, Ruiz Gonzalez A, Merino MT \& Rubio Caballero M. 2000. Diagnosis of pneumococcal pneumonia by polymerase chain reaction (PCR) in whole blood: A prospective clinical study. Thorax. 55: 133-137.

11. Tzanakaki G, Tsapanomichaloa, Kesanopoalos K, Matzourani R, Sioumala M, Tabaki A \& Kremastinou J. 2005. Simultaneous singletube PCR assay for the detection of Neisseria meningitides, Haemophilus influenzae type $\mathrm{b}$ and Streptococcus pneumoniae. Clin Microbiol Infect. 11(5): 386-390.

12. Marston BJ, Plouffe JF, File TM, Hackman BA, Salstrom SJ, Lipman HB, Kolczak MS \& Breiman RF. 1997. Incidence of community-acquired pneumonia requiring hospitalization. Results of a population-based active surveillance Study in Ohio. The Community-Based Pneumonia Incidence Study Group. Arch Intern Med. 157: 1709-1718.

13. Garcia A, Rosón B, Perez JL, Verdaguer R, Dorca J, Carratala J, Casanova A, Manresa F \& Gudiol F. 1999. Usefulness of PCR and antigen latex agglutination test with samples obtained by transthoracic needle aspiration for diagnosis of pneumococcal pneumonia. J Clin Microbiol. 37(3):709-714.
14. Saha SK, Darmstadt GL, Tamanaka N, Billal DS, Nasreen T, Islam M \& Hamer DH. 2005. Rapid diagnosis of pneumococcal meningitis: Implications for treatment and measuring disease burden. Pediatr Infect Dis J. 24(12): 1093-1098.

15. Dominguez J, Gali N, Blanco S, Pedroso P, Prat C, Matas L \& Ausina V. 2001. Detection of Streptococcus pneumoniae antigen by a rapid immunochromatographic assay in urine samples. Chest. 119(1): 243-249.

16. Marcos MA, Jiménez de Anta MT, de la Bellacasa JP, González J, Martínez E, García E, Mensa J, de Roux A and Torres A. 2003. Rapid urinary antigen test for diagnosis of pneumococcal community-acquired pneumonia in adults. Eur Respir J. 21: 209-214.

17. Goldsmith CE, Moore JE \& Murphy PG. 1997. Pneumococcal resistance in the UK. J Antimicrob Chemother. 40(Suppl A): 11-18.

18. Oster P, Zanchi A, Cresti S, Lattanzi M, Montagnani F, Cellesi C \& Rossolini GM. 1999. Patterns of macrolide resistance determinants among community-acquired Streptococcus pneumoniae isolates over a 5 -year period of decreased macrolide susceptibility rates. Antimicrob Agents Chemother. 43(10): 2510-2512.

19. Saha SK, Rikitomi N, Biswas D, Watanabe K, Ruhulamin M, Ahmed K, Hanif M, Matsumoto K, Sack RB \& Nagatake T. 1997. Serotypes of Streptococcus pneumoniae causing invasive childhood infections in Bangladesh, 1992 to 1995. J Clin Microbiol. 35(3): 785-787.

20. Saha SK, Khan WA, Hoq MS, Selim AF \& Akbar MS. 1991. Penicillinresistant pneumococci in Bangladeshi children. Lancet. 337(8743): 734-735.

21. Alam MR, Saha SK, Nasreen T, Latif F, Rahman SR \& Gomes DJ. 2006. A laboratory-based aetiologic diagnosis of childhood bacterial meningitis in Bangladesh. Bangladesh J Med Sci. 12(2): 120-126.

22. Cappucino JG \& Sherman N. 1996. Microbiology - A Laboratory Manual, $4^{\text {th }}$ edn, pp 477. The Benjamin Cummings Publishing Co, Inc, Menlo Park, California.

23. NCCLS. 2002. Performance of standards for antimicrobial susceptibility testing, $12^{\text {th }}$ Informational Supplement, Vol. 22(1). NCCLS document M100-S12. National Committee for Clinical Laboratory Standards (NCCLS), Wayne, Pennsylvania.

24. Jorgensen JH, Howell AW \& Maher LA. 1991. Quantitative antimicrobial susceptibility testing of Haemophilus influenzae and Streptococcus pneumoniae by using the E-test. J Clin Microbiol. 29:109-114.

25. Facklam RR \& JA Washington II. 1991. Streptococcus and related catalase-negative Gram-positive cocci. In Manual of Clinical Microbiology (Balows A, Hausler Jr WJ, Hermann K, Isenberg HD \& Shadomy HJ eds), $5^{\text {th }}$ edn, pp 238-257. American Society for Microbiology, Washington DC.

26. Nathan BR \& Scheld WM. 2000. New advances in the pathogenesis and pathophysiology of bacterial meningitis. Curr Infect Dis Rep. 2(4): 332-336.

27. Saha SK, Baqui AH, Darmstadt GL, Ruhulamin M, Hanif M, El Arifeen S, Santosham M, Oishi K, Nagatake T \& Black RE. 2003. Comparison of antibiotic resistance and serotype composition of carriage and invasive pneumococci among Bangladeshi children: Implications for treatment policy and vaccine formulation. J Clin Microbiol. 41(12): 5582-5587.

28. Baraff LJ, Lee SI \& Schriger DL. 1993. Outcomes of bacterial meningitis in children: A meta-analysis. Pediatr Infect Dis J. 12: 389-394.

29. Aronin SI. 2000. Bacterial meningitis: Principles and practical aspects of therapy. Curr Infect Dis Rep. 2(4): 337-344.

30. Breiman RF, Butler JC, Tenover FC, Elliot JA, Facklam RR. 1994. Emergence of drug-resistant pneumococcal infections in the United States. J Am Med Assoc. 271: 1831-1835. 
31. Friedland IR \& McCracken GH. 1994. Management of infections caused by antibiotic-resistant Streptococcus pneumoniae. New Eng J Med. 331(6): 377-382.

32. Hsueh PR, Teng LJ, Lee LN, Yang PC, Ho SW \& Luh KT. 1999. Extremely high incidence of macrolide and trimethoprimsulphamethoxazole resistance among clinical isolates of Streptococcus pneumoniae in Taiwan. J Clin Microbiol. 37: 897-901.

33. Lee NY, Song JH, Kim S, Peck KR, Ahn KM, Lee SI, Yang Y, Li J, et al. 2001. Carriage of antibiotic resistant pneumococci among Asian children: A multinational surveillance by the Asian network for surveillance of resistant pathogens (ANSORP). Clin Infect Dis. 32(10): 1463-1469.

34. Bangladesh Ministry of Health \& Family Welfare. 1993. CARI (Care for Acute Respiratory Infection) project: Management of the young child with an acute respiratory infection. Directorate General of Health Services, Government of Bangladesh, Dhaka, Bangladesh.

35. Whitney CG, Farley MM, Hadler J, Harrison LH, Lexau C, Reingold A, et al. 2000. Increasing prevalence of multidrug-resistant Streptococcus pneumoniae in the United States. $N$ Engl J Med. 343(26): 1917-1924.

36. Maugein J, Guillemot D, Dupont MJ, Fosse T, Laurans G, RousselDelvallez M, Thierry J, Vergnaud M, Weber M \& Poirier B. 2003. Clinical and microbiological epidemiology of Streptococcus pneumoniae bacteremia in eight French countries. Clin Microbiol Infect. 9: 280-288.

37. Lehmann D, Gratten M \& Montgomery J. 1997. Susceptibility of pneumococcal carriage isolates to penicillin provides a conservative estimate of susceptibility of invasive pneumococci. Pediatr Infect Dis J. 16: 297-305. 